\title{
Design Features Associated with User Engagement in Digital Games for Healthy Lifestyle Promotion in Youth: A Systematic Review of Qualitative and Quantitative Studies
}

\author{
Ayla F. Schwarz, PhD, ${ }^{1}$ Francisco J. Huertas-Delgado, PhD, ${ }^{2}$ Greet Cardon, PhD, and Ann DeSmet, PhD ${ }^{1,3}$
}

\begin{abstract}
User engagement in digital (serious) games may be important to increase their effectiveness. Insights into how to create engaging games for healthy lifestyle promotion are needed, as despite their potential, not all digital (serious) games are highly engaging. This study systematically reviewed game features that were associated with higher user engagement among youth. A systematic search was conducted in PubMed, Web of Science, CINAHL, and PsycARTICLES databases. Qualitative and quantitative studies were included, if they documented game features associated with youth engagement. Coding of game features was performed using the mechanics-dynamics-aesthetics (MDA) framework. A total of 60 studies met the inclusion criteria and were included in the registered systematic review (No. CRD42018099487). Results showed that various game features were associated with user engagement in digital (serious) games: an attractive storyline, adaptable to gender and age, including diverse (antagonist) characters the user may identify with, high-end realistic graphics, well-defined instructions, which can be skipped, in combination with clear feedback and a balance of educational and fun content. This review underpinned the relevance of investigating engaging game features specifically for youth, as deviations were found with characteristics that are engaging for other populations.
\end{abstract}

Keywords: Engagement, Serious game, Health, Youth, Systematic review

\section{Introduction}

$\mathbf{Y}$ OUTH HEALTHY LIFESTYLE PROMOTION is important to prevent the risk of developing noncommunicable diseases at a later age, including diabetes type 2, certain forms of cancer, and cardiovascular diseases. ${ }^{1-3}$ Healthy lifestyle behaviors are moreover associated with a higher sense of wellbeing among youth. ${ }^{4}$ A healthy lifestyle covers a range of behaviors, including exercise/physical activity; a healthy diet; health responsibility/maintenance (e.g., regular doctor visits); social behavior; and mental health, including stress management and self-actualization. ${ }^{5-8}$ Around two-thirds of children and adolescents show more than one unhealthy lifestyle behavior. ${ }^{6}$ Since established lifestyle patterns in childhood or adolescence often track into adulthood, ${ }^{9}$ interventions that address healthy lifestyle behaviors among youth are needed. ${ }^{10}$

Many systematic reviews and meta-analyses have underscored the potential of serious digital games to promote healthy lifestyle behaviors among youth and adults. ${ }^{8,11-16}$ Serious digital games are a form of organized play that contain a challenge, rules, rewards or feedback, and are intended to be both entertaining and educational. ${ }^{17}$ To be effective, it is important that users experience a sufficient degree of engagement with the game, ${ }^{18}$ otherwise known as effective engagement, or the sufficiently subjective engagement and behavior to achieve desired and positive outcomes. ${ }^{18}$ User engagement in games is defined as the involvement and motivation of the player in game play, ${ }^{19}$ and can be conceptualized in terms of subjective engagement or experience (e.g., attention, interest, and affect) and behavior (e.g., usage) ${ }^{20}$ Higher user engagement in digital (serious) games was associated with continued play, increased attention, and potentially increased game effects. ${ }^{21-23}$

As such, digital games may overcome motivational barriers related to low usage, early dropout, or even nonusage, currently faced in many health promotion programs. ${ }^{24-27}$ To the best of our knowledge, few studies have, however, examined the association between game engagement and effectiveness. The available research confirmed that higher engagement was associated with higher effectiveness in healthy lifestyle promotion among adolescents and young adults. ${ }^{22,28,29}$

\footnotetext{
${ }^{1}$ Department of Movement and Sport Sciences, Ghent University, Ghent, Belgium.

${ }^{2}$ Department of Didactic of Musical, Plastical and Body Expression, La Inmaculada Teacher Training Centre, University of Granada, Granada, Spain.

${ }^{3}$ Research Foundation Flanders, Brussels, Belgium.
} 
Given the potential crucial role of user engagement for game effectiveness, it is important to know how to design games that can yield higher user engagement. Research has demonstrated that playing against a human-controlled opponent, being technology advanced, including sound or music, ${ }^{21}$ suspense, ${ }^{21}$ a story, ${ }^{21,30}$ positive reinforcement, ${ }^{21}$ a buddy, ${ }^{31}$ feedback, and controller use, ${ }^{32}$ competitive or cooperative play ${ }^{33}$ was associated with higher game engagement. However, these findings stem from studies among adults or broad target groups in terms of age, and did not specifically address games for healthy lifestyle promotion or studies among youth.

To date, studies investigating game features (i.e., prominent game elements that define what a game entails) of engagement for digital games in healthy lifestyle promotion among youth are scarce. ${ }^{34,35}$ Investigating features separately for this age group (6-18 years) is, however, needed, since user engagement is thought to differ between youth and adults due to cognitive differences. ${ }^{20}$ The aim of this study was to conduct a systematic review on game features associated with youth's subjective engagement with digital (serious) games for healthy lifestyle promotion.

\section{Materials and Methods}

The research protocol was registered with the International Prospective Register of Systematic Reviews (PROSPERO) at www.crd.york.ac.uk/prospero (No. CRD42018099487). Reporting complied with the Preferred Reporting Items for Systematic Reviews and Meta-Analyses (PRISMA) statement ${ }^{36}$ (Supplementary Table S1).

\section{Search strategy and eligibility}

Four electronic bibliographic databases were searched for relevant articles: PubMed ( $\left.{ }^{\circ} 1966\right)$, Web of Science $\left({ }^{\circ} 1926\right)$, CINAHL $\left({ }^{\circ} 1937\right)$, and PsycARTICLES $\left({ }^{\circ} 1894\right)$. The search was limited to articles published between January 2000 and end of November 2018 and was conducted using keywords listed in Table 1. Both the strategy and keywords are listed in Table 1 and are partly based on an earlier meta-analysis on serious games and health. ${ }^{8}$ In addition, relevant studies were identified from bibliographies in relevant reviews. $811,12,21,37-42$

For all qualifying articles, relevant studies were identified independently by screening titles and abstracts, by one researcher and one-third by a second researcher. Next, full texts were read independently to determine final eligibility, by one researcher and one-third by a second researcher. Qualitative or quantitative studies among 6-18-year olds investigating game features in relation to user engagement as subjective experience with a digital game for healthy lifestyle promotion were included. Table 1 lists full inclusion and exclusion criteria.

\section{Data extraction and synthesis}

Data extraction was completed by one reviewer (A.F.S.) and one-third $(n=19)$ was checked by another reviewer (A.D.S.) for accuracy. The following information was extracted by both reviewers: game features associated with engagement (e.g., graphics), measure of engagement (e.g., fun), and health domain (e.g., physical activity). Features and engagement were used based on their descriptions in the articles, and not based on coding based on classified categories. Disagreement regarding data extraction was resolved through discussion between reviewers (A.F.S. and A.D.S.). Inter-rater reliability was almost perfect $(\kappa=0.92){ }^{46}$ Descriptive information (e.g., authors, publication year, and health topic) is provided in Supplementary Table S2.

\section{MDA framework, behavioral change techniques, and genre}

Game features were coded with a coding frame based on the mechanics-dynamics-aesthetics (MDA) framework ${ }^{47}$ (Supplementary Table S3), which describes key game elements that can influence experience. The framework is developed from a game-based learning theory in game design and is often used in game research. It contains three components: game mechanics, dynamics, and aesthetics (Table 2). Mechanics are the basic components of the game, such as rules, basic actions, and the data structure of the game (e.g., game controller). Dynamics are the runtime behavior of the game and focuses on the interactions with the player (e.g., feedback).

Game aesthetics are the emotional responses of the player when he/she interacts with the game (e.g., narrative). The framework added a taxonomy of eight types of aesthetics: (1) sensation: players experience something completely unfamiliar, their senses are triggered (e.g., graphics); (2) fantasy: players engage in an imaginary world (e.g., role playing); (3) narrative: players follow a story that drives the player to keep coming back (e.g., identification with characters); (4) challenge: players master a certain level that boosts replayability (e.g., side missions); (5) fellowship: players are part of a community, as in multiplayer games (e.g., competition); (6) discover: players explore the game world (e.g., quests); (7) expression: players create their own characters as avatar and can express themselves by their creativity (e.g., customization); and (8) submission: players engage in the game to past time and are not distracted by any constraints (e.g., enjoyment).

The coding frame was developed in consensus by two behavior scientists (A.D.S. and A.F.S.) and one external game developer. Features were coded as belonging to one single MDA component to which it fits best, although it is important to note that components are closely linked to each other.

Some elements related to behavior change techniques (BCTs) that did not fit the MDA framework. These were coded with a taxonomy of BCTs (e.g., personal goal setting). ${ }^{48}$ In addition, game genre (i.e., category of games that relates to similar game play characteristics) is not part of the MDA framework, and was coded separately (e.g., adventure). ${ }^{49}$

\section{Engagement}

A coding frame for engagement emerged from the individual studies' engagement construct and were categorized into five categories (i.e., engagement, affective engagement, perceived usability, interest, and immersion) based on dimensions from validated game engagement questionnaire $\mathrm{s}^{20,50-52}$ (Table 3). After extracting the engagement dimension of the original study (e.g., acceptability), it was coded according to the fivecategory coding frame (e.g., perceived usability).

Whereas engagement refers to the overall assessment of engagement, affective engagement refers to measures of 
Table 1. Detailed Selection Criteria for Inclusion and Exclusion of Studies in This Review

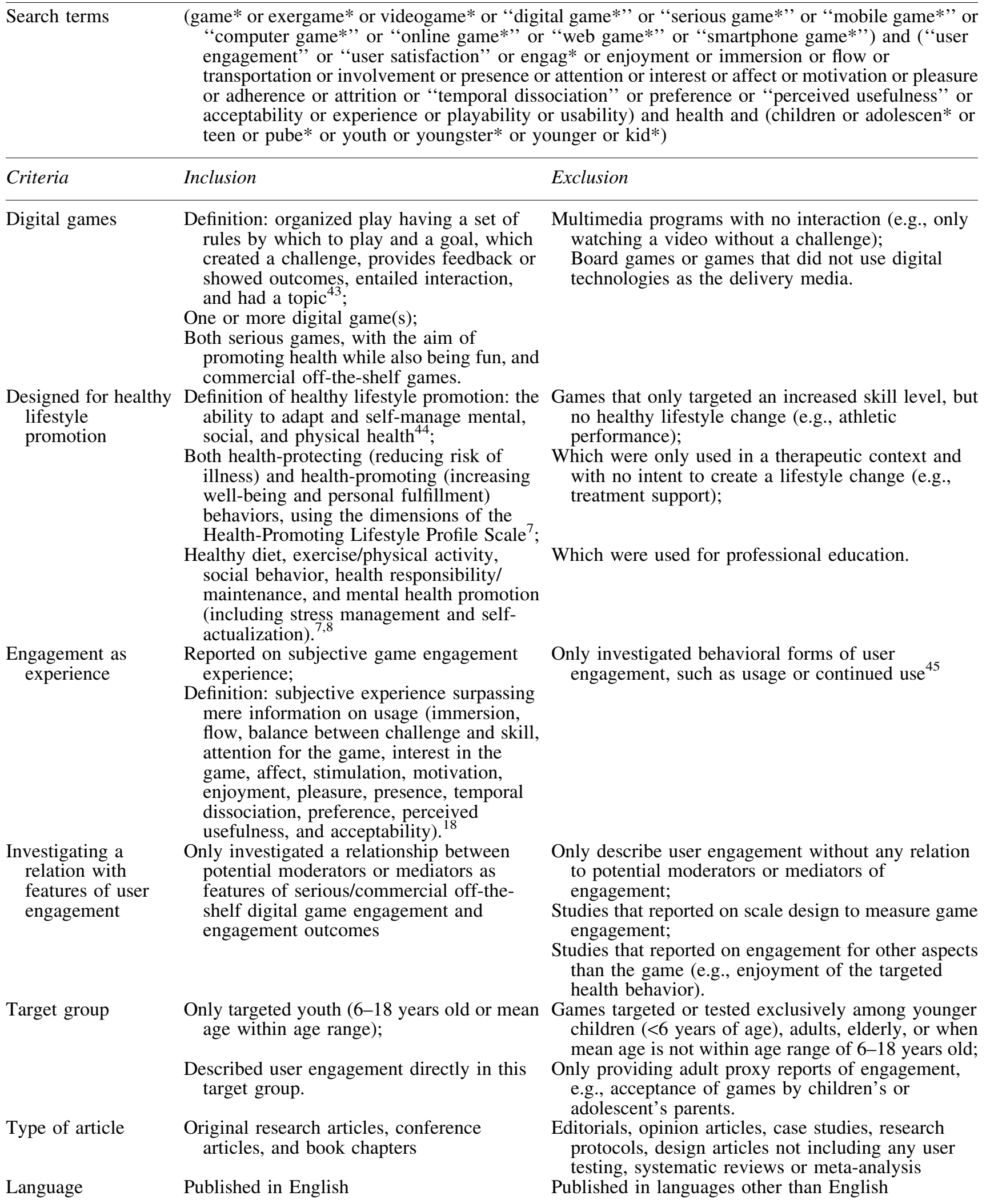


Table 2. Mechanics-Dynamics-Aesthetics Framework, Genre, and Behavioral Change Techniques

\begin{tabular}{|c|c|c|}
\hline$M D A$ & Definition & Examples \\
\hline Mechanics & $\begin{array}{l}\text { Basic components of the game, as rules, basic actions, and the data } \\
\text { structure of the game }\end{array}$ & $\begin{array}{l}\text { Game controller, device } \\
\text { requirement, platform }\end{array}$ \\
\hline Dynamics & $\begin{array}{l}\text { Runtime behavior of the game and focus on the interactions with the } \\
\text { player }\end{array}$ & Feedback, rewards, game goals \\
\hline \multirow[t]{10}{*}{ Aesthetics } & $\begin{array}{l}\text { Emotional responses and interactions of the player when he/she interacts } \\
\text { with the game (e.g., enjoying to jump) }\end{array}$ & \\
\hline & Taxonomy & \\
\hline & $\begin{array}{l}\text { 1. sensation: experiencing something completely unfamiliar, which } \\
\text { triggers their senses; }\end{array}$ & 1. Graphics, sounds, and language \\
\hline & $\begin{array}{l}\text { 2. fantasy: engaging in an imaginary world; not being able to be in real } \\
\text { life; }\end{array}$ & 2. Role playing \\
\hline & $\begin{array}{l}\text { 3. narrative: following a story that drives the player to keep coming } \\
\text { back; }\end{array}$ & 3. Identification with characters \\
\hline & 4. challenge: mastering a certain level that boosts replayability; & 4. Different levels or side missions \\
\hline & 5. fellowship: being part of a community, as in multiplayer games; & 5. Competition, cooperation \\
\hline & 6. discovery: finding new things, exploring the game world; & 6. Quests \\
\hline & 7. expression: ability of players to express own creativity in game; & $\begin{array}{l}\text { 7. Customization and making } \\
\text { autonomous choices }\end{array}$ \\
\hline & $\begin{array}{l}\text { 8. submission: engaging in the game to pass time and not being } \\
\text { distracted by any constraints (not coded). }\end{array}$ & $\begin{array}{l}\text { 8. Enjoyment, engagement, flow in } \\
\text { game (not coded) }\end{array}$ \\
\hline Genre & Category of games that relates to similar game play characteristics & Action/adventure \\
\hline $\mathrm{BCT}$ & $\begin{array}{l}\text { Theory-based techniques for changing one or several psychological } \\
\text { determinants of human behavior }\end{array}$ & $\begin{array}{l}\text { Shaping knowledge, personal goal } \\
\text { setting, and self-monitoring }\end{array}$ \\
\hline
\end{tabular}

The categories of the MDA framework were based on earlier reference, ${ }^{47}$ and otherwise in collaboration with the game developer. BCT, behavior change technique; MDA, mechanics-dynamics-aesthetics.

the affective state only (e.g., enjoyment). Perceived usability refers to the user experience (e.g., acceptability), interest refers to the cognitive state (e.g., perceived relevance), and immersion refers to perceived state of being in the game (e.g., transportation). Measures of engagement included validated scales (e.g., electronic game use anxiety scale), quantitative scales (e.g., emoticons), or qualitative assessments of engagement in focus groups (e.g., preferences and acceptability).

\section{Quality assessment}

Two scoring systems assessed the studies' quality: the appraising tool of qualitative evidence ${ }^{53}$ and Effective Public Health Practice Project assessment tool for quantitative

Table 3. Coding Frame for User Engagement

\begin{tabular}{lc}
\hline Engagement categories & \multicolumn{1}{c}{ Engagement measures } \\
\hline Engagement & $\begin{array}{c}\text { Engagement measured as overall } \\
\text { concept } \\
\text { Affective engagement } \\
\text { (positive or negative) } \\
\text { Peasures of anxiety, arousal, } \\
\text { affect, enjoyment, fun, } \\
\text { satisfaction, and liking } \\
\text { Measures of experience (user } \\
\text { friendliness), acceptability, } \\
\text { usability, playability, and } \\
\text { mobility } \\
\text { Measures of interest, preference, } \\
\text { perceived relevance, } \\
\text { interest }\end{array}$ \\
importance, and motivation \\
Measures of immersion, \\
transportation, and self- \\
presence
\end{tabular}

studies. ${ }^{54}$ For the assessment of mixed-method studies, both tools were used. Quality assessment was not used as a basis for study exclusion, but to support result interpretation. All studies were coded on quality (A.F.S.) and a third was double coded (A.F.S. and F.J.H.D.), inter-rater reliability was almost perfect $(\kappa=0.96){ }^{46}$

\section{Results}

\section{Description of included studies}

Fifty-five articles that described 60 studies ( $n=5$ mixedmethod studies) on the relationship between game characteristics and subjective user engagement were included (Fig. 1). Most studies originated in North America (26/60) and targeted exercise/physical activity (34/60). Other studies addressed health responsibility/maintenance $(n=17)$, healthy diet $(n=4)$, mental health $(n=2)$, and social support $(n=1)$ (Table 4$)$. There was a large diversity in engagement measures studied, with affective engagement $(n=23 / 60)$ and perceived usability $(n=20 / 60)$ studied most often (Table 5$)$. The majority of studies used a qualitative design (36/60).

An overview of identified game features is listed in Figure 2. Features associated with engagement are summarized in Table 5. Both are ranked according to strength of association, from games features showing the highest associations with engagement to those with the weakest associations with engagement. Results are presented according to the MDA framework elements, genre, and BCTs.

More than half of qualitative studies (58\%) showed good $(18 / 36)$ or fair quality (3/36), whereas $42 \%$ showed poor (14/ $36)$ or very poor quality (1/36). Half of quantitative studies showed moderate $(8 / 24)$ or strong $(4 / 24)$ quality; the other half was of weak quality (12/24) (Supplementary Table S4). 


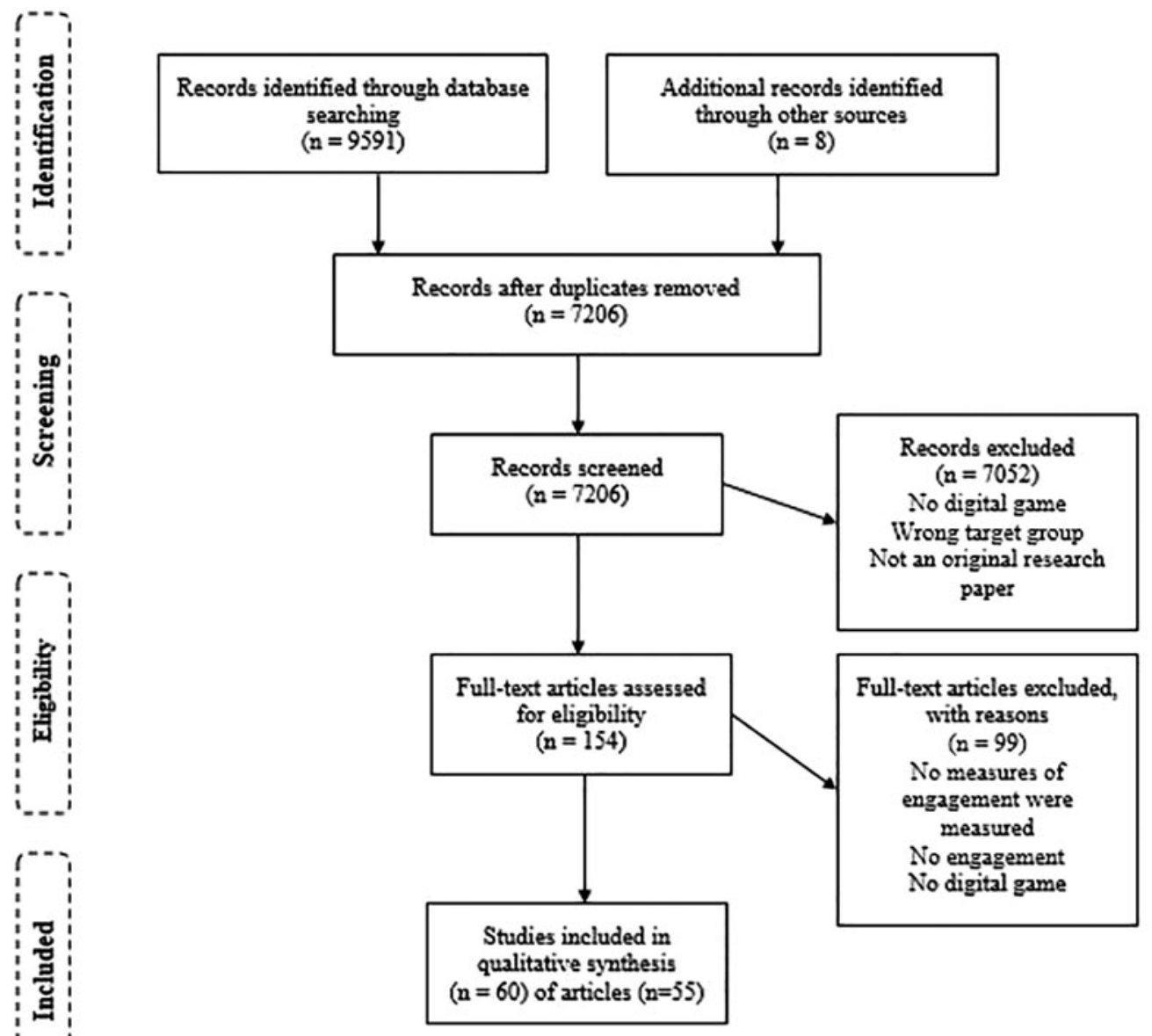

FIG. 1. Flow chart of included studies.

Weak quality in quantitative studies was mainly due to a nonexperimental study design, potential for selection bias, and lack of controlling for confounders. In qualitative studies, weak quality was especially due to weak type of data analyses, lack of description of ethics or researcher bias, and limited info on sampling or generalizability.

\section{Aesthetic features}

Challenge (23/60 studies). In general, users wanted manageable and easy-to-achieve challenges. ${ }^{55-59}$ Some challenges were experienced as too hard, ${ }^{60-64}$ especially by girls. ${ }^{65}$ In active videogames, children and adolescents preferred low rather than high physical intensity. ${ }^{66}$ Complex movements or a fast pace resulted in player frustration. ${ }^{66}$ Youth generally preferred to have different levels of challenges, ${ }^{67-69}$ either by having several side missions, ${ }^{60,70,71}$ levels of increasing difficulty level, ${ }^{72}$ or difficulty level tailored by age. ${ }^{73,74}$ When a challenge was met, children experienced a sense of mastery, but they disliked having to keep trying unsuccessfully. ${ }^{73}$ Unexpected traps and obstacles were considered to make a challenge even more fun. ${ }^{75}$

Narrative (11/60) and character identification (17/ 60). Identification with characters was significantly associated with immersion. ${ }^{30,76}$ Youth preferred a high degree of realism and (cultural or body development related) similarity of the characters to themselves. ${ }^{30,63,75,77-79}$ A preference for high realism did not preclude an interest in fantasy and other nonhuman characters, mainly as antagonists and especially among young children. ${ }^{80,81}$ Human characters were generally preferred as protagonists. ${ }^{80,81}$ Youth also mentioned transitional characters, who would change from being bad to good. ${ }^{80}$ There was also a preference for a higher number of diverse characters in the game. ${ }^{58,60,70,71,82}$ Older adolescents preferred more complex characters with ambivalent personalities. ${ }^{80}$ One study mentioned a preference for a fit between the characters and the health topic in the game. ${ }^{74}$ Characters, however, seemed to be less important for engagement than the storyline, ${ }^{77}$ which was considered as very important. ${ }^{60,67,77,83}$ Having a narrative in the game was preferred to a nonnarrative game. ${ }^{82}$ Important aspects of the storyline were its originality, ${ }^{77}$ especially among older youth ${ }^{78}$; that it fits their personal life, in terms of both realism ${ }^{59,81,83}$ and their cognitive abilities ${ }^{77}$; and that it has a sufficiently high pace. ${ }^{78} \mathrm{~A}$ narrative that could facilitate transfer of the learned behavior to real life (e.g., conversations with parents and partners about sexual health) was appreciated. ${ }^{69}$ Preferences for storylines included fight scenes, mainly among boys ${ }^{82}$; conflicts (crime, catastrophe, and war); and professional skill development, mainly among girls. ${ }^{81}$

Sensation: graphics (13/60), music (8/60), and language $(2 / 60)$. Graphics and animations, that is, digital representation 
Table 4. Overview of Game Features Studied in Particular Health Domain

\begin{tabular}{|c|c|c|c|c|c|c|c|}
\hline & $\begin{array}{l}\text { Exercisel } \\
\text { physical } \\
\text { activity }\end{array}$ & $\begin{array}{c}\text { Health } \\
\text { responsibility/ } \\
\text { maintenance }\end{array}$ & $\begin{array}{c}\text { Healthy } \\
\text { diet }\end{array}$ & $\begin{array}{c}\text { Mental health } \\
\text { promotion }\end{array}$ & $\begin{array}{l}\text { Overall } \\
\text { health }\end{array}$ & $\begin{array}{c}\text { Social } \\
\text { behavior }\end{array}$ & $\begin{array}{l}\text { Total } \\
\text { number of } \\
\text { studies }\end{array}$ \\
\hline \multicolumn{8}{|l|}{ Aesthetics } \\
\hline Challenge & 13 & 5 & 3 & 2 & 0 & 0 & 23 \\
\hline Identification with characters & 8 & 4 & 1 & 2 & 1 & 1 & 17 \\
\hline Graphics & 8 & 3 & 0 & 1 & 0 & 1 & 13 \\
\hline Customization & 5 & 3 & 1 & 1 & 1 & 1 & 12 \\
\hline Narrative & 6 & 3 & 0 & 0 & 1 & 1 & 11 \\
\hline Music/sound & 5 & 2 & 1 & 0 & 0 & 0 & 8 \\
\hline Competition & 6 & 1 & 0 & 0 & 0 & 0 & 7 \\
\hline Cooperation & 5 & 1 & 0 & 0 & 0 & 0 & 6 \\
\hline Creative freedom & 5 & 1 & 0 & 0 & 0 & 0 & 6 \\
\hline Community & 3 & 1 & 0 & 1 & 0 & 0 & 5 \\
\hline Language & 1 & 0 & 0 & 1 & 0 & 0 & 2 \\
\hline Discovery & 2 & 0 & 0 & 0 & 0 & 0 & 2 \\
\hline Fantasy & 0 & 1 & 0 & 0 & 0 & 0 & 1 \\
\hline \multicolumn{8}{|l|}{ Dynamics } \\
\hline Rewards & 12 & 5 & 0 & 1 & 0 & 0 & 18 \\
\hline Feedback & 7 & 2 & 0 & 0 & 0 & 0 & 9 \\
\hline Instruction & 7 & 2 & 0 & 0 & 0 & 0 & 9 \\
\hline Time limits & 2 & 4 & 0 & 0 & 0 & 0 & 6 \\
\hline Active vs. passive game play & 5 & 0 & 0 & 0 & 0 & 0 & 5 \\
\hline Game goals & 3 & 0 & 0 & 0 & 0 & 0 & 3 \\
\hline \multicolumn{8}{|l|}{ Mechanics } \\
\hline Device and media requirement & 7 & 3 & 0 & 0 & 0 & 0 & 10 \\
\hline Game controller & 4 & 4 & 2 & 0 & 0 & 0 & 10 \\
\hline Genre & 4 & 2 & 0 & 1 & 0 & 0 & 7 \\
\hline \multicolumn{8}{|l|}{ BCTs } \\
\hline Shaping knowledge & 2 & 7 & 1 & 0 & 1 & 0 & 11 \\
\hline Personal goal setting & 1 & 1 & 0 & 0 & 0 & 0 & 2 \\
\hline Self-monitoring & 1 & 1 & 0 & 0 & 0 & 0 & 2 \\
\hline
\end{tabular}

of nontext information, were considered as very important by users, ${ }^{59,67,84}$ whereas animation, that is, appearance of motion created by displaying a series of still images in sequence, was less important. ${ }^{77}$ Graphics were liked when showing high resolution, ${ }^{85}$ three-dimensional, ${ }^{59,70,77}$ and realistic ${ }^{59,74,75,86}$; having a cartoon look ${ }^{86}$; colorful graphics ${ }^{75}$; showing real movement ${ }^{82}$; or animation in the background. ${ }^{75}$ In general, adolescents highly valued the integration of music and sounds. $^{64}$

Well-liked types of music and sounds were "spooky sounds," 68 realistic sound effects that matched the challenge; which reflected their movement ${ }^{75}$ and had several
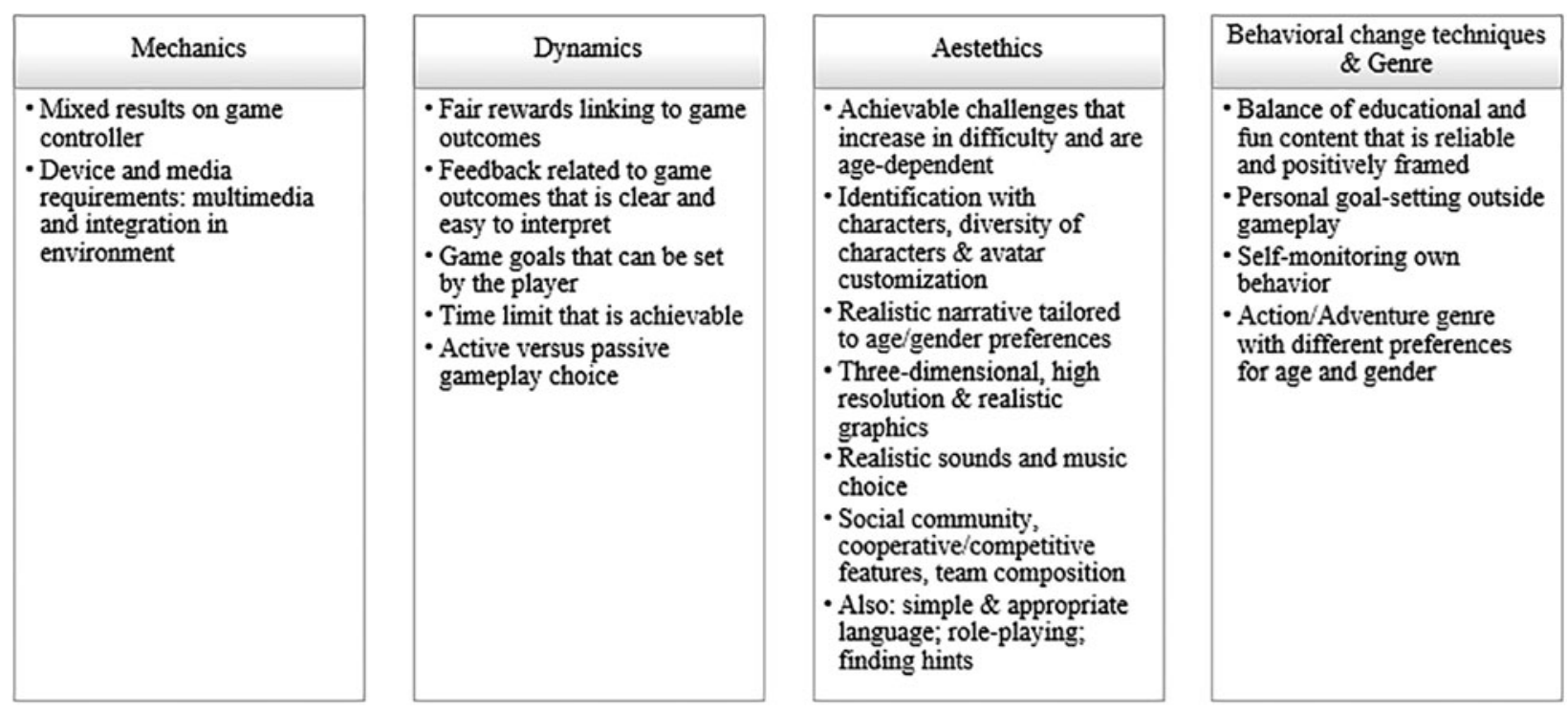

FIG. 2. Features contributing to engagement in digital (serious) games among youth. 
Table 5. Overview of Established Associations with Engagement Measures

\begin{tabular}{|c|c|c|c|c|c|c|}
\hline & $\begin{array}{c}\text { Affective } \\
\text { engagement }\end{array}$ & Interest & Immersion & $\begin{array}{c}\text { Perceived } \\
\text { usability }\end{array}$ & $\begin{array}{c}\text { Overall } \\
\text { engagement }\end{array}$ & $\begin{array}{c}\text { Total number } \\
\text { of studies }\end{array}$ \\
\hline \multicolumn{7}{|l|}{ Aesthetics } \\
\hline Challenge & $4 / 8$ & $3 / 4$ & $1 / 1$ & $6 / 8$ & $1 / 2$ & $15 / 23$ \\
\hline Identification with characters & $4 / 4^{\mathrm{a}}$ & $2 / 4$ & $5 / 5^{\mathrm{a}}$ & $4 / 4$ & $0 / 0$ & $17 / 17$ \\
\hline Graphics & $2 / 2$ & $2 / 3$ & $1 / 1$ & $6 / 6$ & $1 / 1$ & $12 / 13$ \\
\hline Customization & $2 / 2$ & $2 / 5$ & $2 / 2$ & $3 / 3$ & $0 / 0$ & $9 / 12$ \\
\hline Narrative & $4 / 4$ & $4 / 4$ & $1 / 1$ & $2 / 2$ & $0 / 0$ & $11 / 11$ \\
\hline Music/sound & $3 / 4$ & $0 / 1$ & $0 / 0$ & $1 / 3$ & $0 / 0$ & $4 / 8$ \\
\hline Competition & $1 / 2$ & $4 / 5$ & $0 / 0$ & $0 / 0$ & $0 / 0$ & $5 / 7$ \\
\hline Cooperation & $1 / 3$ & $1 / 1$ & $0 / 0$ & $2 / 2$ & $0 / 0$ & $4 / 6$ \\
\hline Creative freedom & $1 / 1$ & $2 / 3$ & $0 / 0$ & $2 / 2$ & $0 / 0$ & $5 / 6$ \\
\hline Community & $2 / 2$ & $2 / 2$ & $0 / 0$ & $0 / 1$ & $0 / 0$ & $4 / 5$ \\
\hline Language & $0 / 0$ & $1 / 1$ & $1 / 1$ & $0 / 0$ & $0 / 0$ & $2 / 2$ \\
\hline Discovery & $1 / 1$ & $0 / 1$ & $0 / 0$ & $0 / 0$ & $0 / 0$ & $1 / 2$ \\
\hline Fantasy & $0 / 0$ & $0 / 0$ & $0 / 0$ & $1 / 1$ & $0 / 0$ & $1 / 1$ \\
\hline \multicolumn{7}{|l|}{ Dynamics } \\
\hline Rewards & $5 / 5$ & $4 / 6$ & $1 / 1$ & $6 / 6$ & $0 / 0$ & $16 / 18$ \\
\hline Feedback & $3 / 3$ & $1 / 1$ & $0 / 0$ & $4 / 5$ & $0 / 0$ & $8 / 9$ \\
\hline Instruction & $0 / 3$ & $1 / 2$ & $0 / 0$ & $0 / 4$ & $0 / 0$ & $1 / 9$ \\
\hline Time limits & $1 / 1$ & $0 / 0$ & $0 / 0$ & $2 / 5$ & $0 / 0$ & $3 / 6$ \\
\hline Active vs. passive game play & $2 / 4$ & $1 / 1$ & $0 / 0$ & $0 / 0$ & $0 / 0$ & $3 / 5$ \\
\hline Game goals & $1 / 2$ & $0 / 0$ & $0 / 0$ & $1 / 1$ & $0 / 0$ & $2 / 3$ \\
\hline \multicolumn{7}{|l|}{ Mechanics } \\
\hline Device and media requirement & $1 / 1$ & $2 / 2$ & $0 / 0$ & $4 / 4$ & $0 / 1$ & $8 / 10$ \\
\hline Game controller & $2 / 4$ & $1 / 2$ & $0 / 0$ & $3 / 4$ & $0 / 0$ & $5 / 10$ \\
\hline Genre & $1 / 1$ & $4 / 4$ & $1 / 1$ & $0 / 0$ & $1 / 1$ & $7 / 7$ \\
\hline \multicolumn{7}{|l|}{ BCTs } \\
\hline Shaping knowledge & $2 / 2$ & $3 / 3$ & $0 / 0$ & $6 / 6$ & $0 / 0$ & $11 / 11$ \\
\hline Personal goal setting & $0 / 0$ & $2 / 2$ & $0 / 0$ & $0 / 0$ & $0 / 0$ & $2 / 2$ \\
\hline Self-monitoring & $0 / 0$ & $1 / 2$ & $0 / 0$ & $0 / 0$ & $0 / 0$ & $1 / 2$ \\
\hline
\end{tabular}

Number of studies with an established association/number of studies in which this was investigated.

${ }^{a}$ In one study, affective engagement and immersion were measured jointly; we counted it as part of immersion.

music options. ${ }^{60}$ Not well-liked types of music and sounds were a soundtrack, ${ }^{74,77}$ songs that did not change, ${ }^{84,87}$ and clicking sounds. ${ }^{73}$ Language was mentioned as a feature that should not be inappropriate, ${ }^{77}$ and not too simplistic. ${ }^{70}$

Fellowship: competition (7/60), cooperation (6/60), and community (5/60). Although there were no significant differences between single-player or multiplayer mode in game play arousal ${ }^{88}$ or enjoyment, ${ }^{89}$ youth did prefer several social forms of play. Competitive ${ }^{59,72,90}$ and active videogame play ${ }^{72}$ was more appreciated when with friends. Adolescents, however, preferred to play the game with their parents when handling sensitive topics. ${ }^{68}$ Youth liked being part of a social community when playing a game, ${ }^{67,71,90}$ not for sharing achievements, ${ }^{56}$ but for sending and receiving messages among team mates. ${ }^{91}$

Having an opponent created higher positive affect. ${ }^{88}$ They liked to play against a robot, but slow answering of the robot also led to frustration. ${ }^{92}$ A danger of overcompetition was mentioned, where schools competed against each other, which resulted in rivalry and frustration. ${ }^{93}$ Youth were also interested in cooperative features. ${ }^{55,83,86}$ Boys less often had a preference for cooperative, competitive, or single-player games. They more often chose team competition ${ }^{90}$ than girls. ${ }^{77}$ Girls chose (individual) competitive play as their most preferred player mode. ${ }^{77,90}$
Expression: customization (12/60) and creative freedom $(6 / 60)$. Users wanted to be able to change the looks of characters and game objects, ${ }^{63,70,74,80,81,86}$ by skin tones, ${ }^{69,77,82}$ body, ${ }^{77}$ hair, ${ }^{77}$ eye color, ${ }^{77}$ facial features, ${ }^{77}$ colors, ${ }^{77}$ clothes, ${ }^{77,82}$ fashion, ${ }^{78}$ and accessories. ${ }^{77}$ Limited options to avatar customization inhibited game engagement. ${ }^{93}$ In terms of creative freedom, youth preferred to play with friends of the same competence level ${ }^{72}$ and to choose their own team members, ${ }^{90}$ although some preferred to be randomly allocated to prevent imbalanced teams. ${ }^{90}$ In active videogames, control in moving their body parts was very important. ${ }^{75}$ Active videogames often provide a set number of sports to imitate, yet, adolescents preferred having free choice on how to move. ${ }^{59}$

Discovery (2/60) and fantasy (1/60). Mixed findings were reported in how important youth considered discovery such as quests and exploration, ${ }^{73,77}$ Only one study assessed fantasy in relation to engagement. Children felt immersion would have been higher if the story had integrated fantasy role playing. 58

\section{Dynamics}

Rewards (18/60). Rewards were generally appreciated, ${ }^{55,67,72,91}$ but most appreciated when not too hard to achieve, ${ }^{74,84}$ handed out fairly, ${ }^{94}$ clearly related to the game objective, $^{62}$ and when there was still room for personal 
improvement (e.g., less appreciated when users reached the top of the leaderboard). ${ }^{95}$ Rewards led to frustration among players who did not win any rewards, but saw other players winning rewards. ${ }^{90}$ Preferred rewards were stars, tokens, gems, or unlocking new game aspects. ${ }^{60,68-70,80}$ Points and leaderboards were not very important. ${ }^{77}$ Older female youth preferred to collect items to customize abilities, weapons, or clothes. Older male youth preferred earning points for new lives, energy, and weapons. ${ }^{80}$ Boys preferred recognitionbased rewards (e.g., trophies), whereas girls preferred material rewards (e.g., vouchers). ${ }^{77}$

Feedback on game performance (9/60). Users preferred to self-monitor their game play (e.g., game progression). ${ }^{55,74,85,86,90,95}$ Receiving feedback on game performance and self-monitoring during game play were generally appreciated. $^{74,75}$ Feedback should be realistic (e.g., applause sound), match game performance (e.g., player failed to stop and as a result falls), ${ }^{75}$ be accurate, and easy to interpret. A dashboard may need to be integrated within game activities and tied to game goals and achievements, as dashboard charts proved difficult to interpret. $^{96}$

Instructions on game play (9/60). Players appreciated information on how to perform the target behavior (e.g., physical activity) in the game. ${ }^{82}$ How these instructions are given may, however, also be a barrier for user engagement when instructions are unclear. ${ }^{58,60,62,95,97,98}$ For example, in one study, users misunderstood the provided suggestions for game activities as mandatory tasks, which limited their perceived choice in the game and reduced their appreciation. $^{91}$ Adolescents suggested including more and clearer instructions. ${ }^{60}$ It is yet uncertain how to best do so: offering a training mission did not result in higher engagement compared with those without training, ${ }^{97}$ and providing instructions on game play in between missions even inhibited engagement. $^{99}$

Time (6/60). Even though time pressure was considered as challenging and fun, ${ }^{58}$ users disliked having to start over with every small error they made, ${ }^{85}$ and not having sufficient time to complete the challenge, ${ }^{74}$ for example, when time provided to complete minigames was too short. ${ }^{62}$ Potential methods to balance time pressure and sense of achievement may lie in using accumulation systems, in which the remaining time of a session was added to available time for a next session, ${ }^{75}$ or in the ability to pause and continue the game, ${ }^{85}$ which could stimulate discussion between peers. ${ }^{79}$ These methods were appreciated by youth. ${ }^{75,79,85}$

Active or passive play mode (5/60). Studies showed mixed results. Quantitative studies showed no significant differences between active game play and passive game play on game anxiety ${ }^{100}$ or enjoyment, ${ }^{101}$ but did show differences in preference, favoring active game play. ${ }^{102,103} \mathrm{~A}$ qualitative study showed that adolescents felt more engaged in active game play than in passive game play. ${ }^{72}$

Game goals (3/60). This was considered the third most important feature in usability testing. ${ }^{75}$ Studies indicated goal setting helps players to adjust the game difficulty, ${ }_{95}$ which makes it individually challenging and achievable. ${ }^{95}$
How goal setting is best provided may be age dependent: calculating points to set goals was too difficult for younger children and reduced their fun. ${ }^{95}$

\section{Mechanics}

Game controllers (10/60). Youth preferred to control the game by voice interaction, ${ }^{85}$ their own body movements, ${ }^{59,75}$ a joystick or handheld controller, ${ }^{59}$ or a mouse rather than LED gloves or hand motion tracking gloves. ${ }^{104}$ Users disliked having to press buttons. ${ }^{73}$ Not knowing how to use controllers, malfunctions or slow response of game controllers increased distraction and reduced usability. $59,62,72,75,98$

Device and media requirements (10/60). The following formats were preferred: (1) a tablet instead of a computer, ${ }^{85}$ (2) integration with real-life environment, ${ }^{61,73}$ (3) integration of different media, ${ }^{65,83,92,105}$ and (4) regular updates with new (e.g., quiz) content. ${ }^{67}$ Devices and media platforms that restricted players to the inside environment (e.g., balance board in an active videogame) were less preferred. ${ }^{57,75}$

Genre (7/60). Genre was considered as highly important by users. ${ }^{77}$ Action/adventure games were generally most preferred. Adolescents also had a preference for fantasy games ${ }^{70}$ or racing games. ${ }^{72}$ Some gender and age differences were noted. Boys preferred racing, sports, fighting, survival, action, and collection. ${ }^{57,59,72,77,80}$ Girls had a preference for life simulation, dancing, singing, sports, puzzle/strategy, racing, and caring for animals. ${ }^{57,59,72,77}$ Elements such as harvesting, jobs, quiz, sports, helping, and caring were of least interest to adolescents. ${ }^{80}$

Age differences included younger adolescents (9-12-year olds) preferred simple games, with no prior training (sports, racing, and adventure), whereas older adolescents (1315-year olds) preferred shooting games and story-based games. ${ }^{106}$ In comparison, younger male adolescents preferred aggressive action and younger female adolescents preferred dance games. ${ }^{57}$ Older male adolescents preferred dance games whereas older female adolescents preferred a game that was related to calorie counting. ${ }^{57}$

\section{Behavior change techniques}

Shaping knowledge information on educational content in serious games (11/60). There were mixed results on whether the game should be announced as educational ${ }^{107}$ or just as a fun game. ${ }^{58,77}$ Various studies showed that adolescents wanted a balance between fun and educational content. ${ }^{60,64,68,74}$ Educational facts should be correct, realistic, trustworthy, ${ }^{67,105}$ nonchildish, nonjudgmental, not lecturing, and presented from the target group's perspective. ${ }^{67}$ Users suggested to emphasize positive effects of the healthy behavior rather than negative effects of the risk behavior. ${ }^{67}$ Whereas some adolescents wanted a variety of health topics, ${ }^{83}$ others suggested to focus on one health topic of the player's choice. ${ }^{108}$

Personal goal setting (2/60) and self-monitoring (1/ 60). Goals are defined in terms of the player's behavior and need to be met outside game play (e.g., glucose level or daily steps). It differs from the game challenge, which directly relates to game play (see game goals). To help the player 
meet the recommended levels of health behavior (e.g., glucose level), users wanted to have goal-setting features in the game. ${ }^{90,107}$ Children showed a preference for a game to include continuous self-monitoring to their health-related behavior (e.g., glucose level). ${ }^{107}$ Users were dissatisfied with the accuracy of the self-monitoring tracker. Data transfer problems between tracker information and game rewards led to further dissatisfaction. ${ }^{94}$

\section{Main findings}

Results showed that various game features were associated with user engagement in digital (serious) games, such as an attractive storyline, adaptable to gender and age, including diverse (antagonist) characters the user may identify with, high-end realistic graphics, well-defined instructions, which can be skipped, in combination with clear feedback and a balance of educational and fun content (Fig. 2).

\section{Discussion}

This systematic review summarized studies that examined associations between game features, such as MDA, and BCTs, and youth's engagement with digital (serious) games for healthy lifestyle promotion. This review was the first to focus exclusively on digital (serious) games for healthy lifestyle promotion among youth.

Aesthetics were examined most in relation to youth game engagement. Especially adding a storyline and ensuring identification with and a diversity of characters were aesthetic aspects that related to higher youth user engagement. Although our review is not the first to point to the importance of these features, ${ }^{30,109,110}$ these features are still only infrequently applied in serious games ${ }^{11,30,111,112}$ and active videogames ("exergames"). 113,114 Our review moreover identified a diversity of characters and antagonists as engaging features, which is an addition to literature that has already reported on the relevance of character identification for game engagement. ${ }^{11,30,35,110}$ Including an attractive storyline that is adaptable to gender and age, with diverse (antagonist) characters that the user may identify with, may hold substantial potential for youth digital (serious) games to be more engaging.

The relevance of high-resolution and three-dimensional realistic graphics was also not yet identified in earlier systematic reviews among youth, ${ }^{110,115}$ and can provide new angles for the design of an engaging game for youth. Our review also reported on achievable challenges; social features such as community, competition, and cooperation; high-end graphics; and avatar customization options, as desirable features for youth engagement. Game aesthetics showed the most consistent positive associations with immersion, which may suggest that aesthetics are especially important for this dimension of engagement. Most studies on aesthetics (with the exception of graphics and customization) were of moderate to high quality, lending support to the robustness of these findings.

Dynamics and mechanics were examined less often than aesthetics in relation to youth game engagement. Studies focused on fair and achievable rewards, clear feedback, and device and media requirements (e.g., integrating different media and integration with their real-life environment), which were all associated with higher user engagement.
Several of these features, such as rewards and feedback, are also well integrated in current digital (serious) games for youth. ${ }^{116}$ Instructions to play the game were not associated with higher user engagement, as users often misunderstood or skipped these. Our findings suggest that giving welldefined instructions which can however be skipped, in combination with clear feedback, is important for user engagement and may present an additional opportunity for more engaging games for youth health promotion.

Dynamics and mechanics were most often studied in relation to perceived usability, affective engagement, and interest. This may suggest that features contributing to the overall functionality of the game (e.g., rules and rewards) are still most often measured in usability studies. ${ }^{117}$ Studies on dynamics (feedback and time limit) and mechanics (game controller) were of poor quality. Results, therefore, need to be interpreted with care. With the exception of studies on rewards, studies that examined dynamics and mechanics were of poor quality. Results, therefore, need to be interpreted with care.

BCTs were not often studied in relation to user engagement, but predominantly showed positive associations, and were reported in high-quality studies. Many (serious) digital games for youth also implement several BCTs, such as personal goal setting and self-monitoring. ${ }^{11,118}$ Providing a balance of fun and education content was identified as an aspect that was important for engagement.

To our knowledge, this review is the first that takes into account the health information presented in digital serious games as an element of engagement. Several studies affirm that educational content and engaging game play need to be well aligned, ${ }^{119,120}$ yet to the best of our knowledge, there are currently no guidelines on how to do so. Our review suggests providing educational facts on health behaviors of the player's choice, which are nonjudgmental or lecturing, emphasize positive effects of the healthy behavior from the target group's perspective, and are not childish for a younger group of youth.

This review started from the assumption that what is important for youth game engagement may differ from what is important for adults and may also differ by the intended purpose of the game (i.e., healthy lifestyle promotion). When comparing results with existing reviews on user engagement in other age groups and topics, some features associated with user engagement appeared shared across age groups and game purposes, but also divergences by age groups were found. Similarities in engagement-enhancing features between youth and adults existed in the importance of cooperation, competition, feedback, challenges, storyline, identification with characters, and sound and music. ${ }^{31-33,121}$ Divergences were found in fantasy, the pace of the game and features that evoke negative emotions as important for adults but not for youth. ${ }^{21,34}$ This underscores the need to examine engagement-enhancing features and design considerations specifically by age of the target group. Both in health- and nonhealth-related games, multimedia elements, storyline, identification with characters, challenges, and rewards were associated with higher user engagement. ${ }^{110,115}$

These findings also highlight some needs for further investigation. First, of the large number of studies on digital (serious) games for health promotion among youth, relatively few had investigated an association with user 
engagement. Moreover, some studies only measured a particular dimension of engagement, whereas engagement is a multidimensional construct. ${ }^{122}$ Widespread use of valid multidimensional measurements of engagement appears to be lacking in evaluation studies of serious games, ${ }^{117}$ and deserves more attention. Second, our review cannot pinpoint which feature is most important for engagement. This would require a meta-analysis of quantitative randomized-controlled trials (RCTs), whereas only three such studies were included.

Moreover, this review describes each feature separately, whereas features may interact and contribute differently to engagement in combination with each other than when used in isolation. The dose and combination of features deserve further research and may be considered to be studied in RCTs, or alternative research designs as experimental factorial design. ${ }^{123}$ Furthermore, it is important to mention that not every person is equally engaged in the same game, ${ }^{124}$ therefore, customization may be further applied to study effective engagement ${ }^{18}$ for individual players. ${ }^{124}$ In addition, a differentiation between healthy versus disease condition may be considered to detect preferences for engaging game features.

\section{Strengths and limitations}

Some limitations need to be noted. Although no publication bias could be assessed due to the inclusion of various types of study designs in our review, the high rate of positive associations among the features that were studied (77\%) may suggest that features that are unrelated or negatively associated with user engagement were not reported in studies or did not get published. This may provide a biased view, overestimating the positive association with user engagement. Moreover, the quality of many included studies was rather low as few experimental studies were found. Currently a diversity of research designs is used to measure correlates of user engagement, which is reflected in this review. Moreover, a variety of engagement measures and dimensions were reported in the individual studies, precluding a direct comparison of results between engagement measures.

Our keywords specifically used the term "game." Older studies may have used other terms such as computer-assisted instruction or simulation. However, our review was restricted to relatively recent literature when the term games was already well established, reducing the risk that relevant studies may have been missed. Moreover, bibliographies of included studies were hand searched to reduce the risk of missing relevant studies.

In this review, the results were structured in terms of the MDA framework, which is usually used in game research and game development. However, we are aware that other concepts could have been used, for example, differentiating between elements of representation and simulation ${ }^{125,126}$ This review did not specify the device on which the game had to be played. This would be of interest to consider in future studies. The review also had several strengths. This review included several studies, investigating engagement in (serious) digital games. Both qualitative and quantitative studies were included, to give a comprehensive overview of the state of the art. The review was conducted in a methodological rigorous manner, using well-established instruments for coding of content and quality, and assessing interrater reliability.

\section{Conclusions}

Various game features such as MDA, but also BCTs, were associated with engagement in digital games for health lifestyle promotion among youth. Aesthetics were examined most often, and positive associations were especially found in relation to immersion. Adding an attractive storyline, adaptable to gender and age, including diverse (antagonist) characters the user may identify with, and high-end realistic graphics may hold substantial potential for increasing youth's engagement in digital (serious) games.

The role of dynamics and mechanics for youth engagement in games was examined less often, but when studied, it especially focused on usability measures. Giving welldefined instructions, which can be skipped, in combination with clear feedback may present an additional opportunity for more engaging games for youth health promotion. BCTs were not often studied in relation to user engagement, but predominantly showed positive associations, especially by providing a balance of educational and fun content.

\section{Acknowledgments}

The authors thank the SmartLife team members, as part of which project these data were collected.

\section{Author Disclosure Statement}

No competing financial interests exist.

\section{Funding Information}

This study was supported by the SmartLife project that was supported by a Horizon 2020 Programme of the European Commission (Grant No. 732348). A.F.S. is funded by the SmartLife project (Grant No. 732348). A.D. is supported by Research Foundation Flanders grant (postdoctoral research fellowship FWO16/PDO/060, 12H6717N). F.J.H-D. was supported by a grant from the Spanish Ministry of Education, Culture and Sport (CAST17/00072). The funding agency had no role in study design, analysis, or report writing.

\section{Supplementary Material}

Supplementary Table S1

Supplementary Table S2

Supplementary Table S3

Supplementary Table S4

\section{References}

1. Singh AS, Mulder C, Twisk JW, et al. Tracking of childhood overweight into adulthood: A systematic review of the literature. Obes Rev 2008; 9:474-488.

2. Nelson MC, Story M, Larson NI, et al. Emerging adulthood and college-aged youth: An overlooked age for weight-related behavior change. Obesity 2008; 16:22052211.

3. Magee L, Hale L. Longitudinal associations between sleep duration and subsequent weight gain: A systematic review. Sleep Med Rev 2012; 16:231-241.

4. Cairns KE, Yap MBH, Pilkington PD, Jorm AF. Risk and protective factors for depression that adolescents can modify: A systematic review and meta-analysis of longitudinal studies. J Affect Disord 2014; 169:61-75. 
5. Chen MY, Wang EK, Yang RJ, Liou YM. Adolescent health promotion scale: Development and psychometric testing. Public Health Nurs 2003; 20:104-110.

6. Alamian A, Paradis G. Clustering of chronic disease behavioral risk factors in Canadian children and adolescents. Prevent Med 2009; 48:493-499.

7. Walker SN, Sechrist KR, Pender NJ. The healthpromoting lifestyle profile: Development and psychometric characteristics. Nurs Res 1987; 36:76-81.

8. DeSmet A, Van Ryckeghem D, Compernolle S, et al. A meta-analysis of serious digital games for healthy lifestyle promotion. Prevent Med 2014; 69:95-107.

9. Viner RM, Ozer EM, Denny S, et al. Adolescence and the social determinants of health. Lancet 2012; 379:16411652.

10. Moreno LA, Gottrand F, Huybrechts I, et al. Nutrition and lifestyle in European adolescents: The HELENA (healthy lifestyle in Europe by nutrition in adolescence) study. Adv Nutr 2014; 5:615S-623S.

11. Baranowski T, Buday R, Thompson D, Baranowski J. Playing for real: Video games and stories for health-related behavior change. Am J Prevent Med 2008; 34:74-82.

12. Barnett A, Cerin E, Baranowski T. Active video games for youth: A systematic review. J Phys Act Health 2011; 8: 724-737.

13. Peng W, Lin J-H, Crouse J. Is playing exergames really exercising? A meta-analysis of energy expenditure in active video games. Cyberpsychol Behav Soc Netw 2011; 14:681-688.

14. Biddiss E, Irwin J. Active video games to promote physical activity in children and youth: A systematic review. Arch Pediatr Adolesc Med 2010; 164:664-672.

15. Cotton V, Patel MS. Gamification use and design in popular health and fitness mobile applications. Am J Health Promot 2018; 33:448-451.

16. Gamberini L, Barresi G, Majer A, Scarpetta F. A game a day keeps the doctor away: A short review of computer games in mental healthcare. J Cyber Ther Rehabil 2008; 1:127-146.

17. Prensky M. Digital game-based learning. Comput Entertain 2003; 1:21.

18. Yardley L, Spring BJ, Riper H, et al. Understanding and promoting effective engagement with digital behavior change interventions. Am J Prevent Med 2016; 51:833842.

19. Crutzen R, van't Riet J, Short CE. Enjoyment: A conceptual exploration and overview of experimental evidence in the context of games for health. Games Health $\mathrm{J}$ 2016; 5:15-20.

20. Perski O, Blandford A, West R, Michie S. Conceptualising engagement with digital behaviour change interventions: A systematic review using principles from critical interpretive synthesis. Transl Behav Med 2016; 7:254 267.

21. Boyle EA, Connolly TM, Hainey T, Boyle JM. Engagement in digital entertainment games: A systematic review. Comput Hum Behav 2012; 28:771-780.

22. Vandebosch H, Herrewijn L, Van Cleemput K, et al. The efficacy of a serious game aimed at the promotion of positive bystander behavior in cyberbullying among adolescents: Examining the role of player experience and player behavior. Poster session presented at International academic conference on Meaningful Play 2016, East Lansing, MI, 2016.
23. Hieftje K, Edelman EJ, Camenga DR, Fiellin LE. Electronic media-based health interventions promoting behavior change in youth: A systematic review. JAMA Pediatr 2013; 167:574-580.

24. Baert V, Gorus E, Mets T, et al. Motivators and barriers for physical activity in the oldest old: A systematic review. Ageing Res Rev 2011; 2011:464-474.

25. McGuire AM, Anderson DJ, Fulbrook P. Perceived barriers to healthy lifestyle activities in midlife and older Australian women with type 2 diabetes. Collegian 2014; 21:301-310.

26. Toobert TJ, Strycker LA, Glasgow RE, Bagdade JE. If you build It, will they come? Reach and Adoption associated with a comprehensive lifestyle management program for women with type 2 diabetes. Patient Educ Couns 2002; 48:99-105.

27. Brennan L, Walkley J, Wilks R. Parent-and adolescentreported barriers to participation in an adolescent overweight and obesity intervention. Obesity 2012; 20:13191324.

28. Peng W, Pfeiffer KA, Winn B, et al. A pilot randomized, controlled trial of an active video game physical activity intervention. Health Psychol 2015; 34:1229.

29. Lyons EJ, Tate DF, Ward DS, et al. Engagement, enjoyment, and energy expenditure during active video game play. Health Psychol 2014; 33:174.

30. Lu AS, Baranowski T, Thompson D, Buday R. Story immersion of videogames for youth health promotion: A review of literature. Games Health J 2012; 1:199204.

31. Feltz DL, Forlenza ST, Winn B, Kerr NL. Cyber buddy is better than no buddy: A test of the Köhler motivation effect in exergames. Games Health J 2014; 3:98-105.

32. Lin JH. "Just Dance": The effects of exergame feedback and controller use on physical activity and psychological outcomes. Games Health J 2015; 4:183-189.

33. Marker AM, Staiano AE. Better together: Outcomes of cooperation versus competition in social exergaming. Games Health J 2015; 4:25-30.

34. Boyle EA, Hainey T, Connolly TM, et al. An update to the systematic literature review of empirical evidence of the impacts and outcomes of computer games and serious games. Comput Educ 2016; 94:178-192.

35. Baranowski T, Blumberg F, Buday R, et al. Games for health for children-Current status and needed research. Games Health J 2016; 5:1-12.

36. Moher D, Liberati A, Tetzlaff J, et al. Preferred Reporting Items for Systematic Reviews and Meta-Analyses: The PRISMA statement. PLoS Med 2009; 6:e1000097.

37. Tabak M, Dekker-van Weering $M$, van Dijk $H$, Vollenbroek-Hutten M. Promoting daily physical activity by means of mobile gaming: A review of the state of the art. Games Health J 2015; 4:460-469.

38. Dias JD, Tibes CMdS, Fonseca LMM, Zem-Mascarenhas SH. Use of serious games for coping with childhood obesity: Integrative literature review. Texto Contexto Enferm 2017; 26:e3010015.

39. Turner T, Spruijt-Metz D, Wen CF, Hingle MD. Prevention and treatment of pediatric obesity using mobile and wireless technologies: A systematic review. Pediatr Obes 2015; 10:403-409.

40. DeSmet A, Palmeira A, Beltran A, et al. The yin and yang of formative research in designing serious (exer-) games. Games Health J 2015; 4:63-66. 
41. LeBlanc AG, Chaput JP, McFarlane A, et al. Active video games and health indicators in children and youth: A systematic review. PLoS One 2013; 8:e65351.

42. Baranowski R, Hoyos-Cespedes L. Nutrition education and dietary behavior change games: A scoping review. Games Health J 2018; 8:153-176.

43. Prensky M. Digital Game-Based Learning: Practical Ideas for the Application of Digital Game-Based Learning. St. Paul, MN: Paragon House; 2007.

44. Huber M, Knottnerus JA, Green L, et al. How should we define health? BMJ 2011; 343:d4163.

45. Lieberman DA. Designing serious games for learning and health in informal and formal settings. In: Ritterfeld U, Cody M, Vorderer P, eds. Serious Games: Mechanisms and Effects. New York, NY: Routledge; 2009, pp. 117-130.

46. Landis JR, Koch GG. The measurement of observer agreement for categorical data. Biometrics. 1977; 33:159-174.

47. Hunicke R, LeBlanc M, Zubek R. MDA: A Formal Approach to Game Design and Game Research. San Jose, CA: AAAI Press; 2004.

48. Michie S, Richardson M, Johnston M, et al. The behavior change technique taxonomy (v1) of 93 hierarchically clustered techniques: Building an international consensus for the reporting of behavior change interventions. Ann Behav Med 2013; 46:81-95.

49. Apperley TH. Genre and game studies: Toward a critical approach to video game genres. Simul Gaming 2006; 37 : 6-23.

50. Brockmyer JH, Fox CM, Curtiss KA, et al. The development of the Game Engagement Questionnaire: A measure of engagement in video game-playing. J Exp Soc Psychol 2009; 45:624-634.

51. IJsselsteijn W, De Kort Y, Poels K. The Game Experience Questionnaire. Eindhoven, the Netherlands: Technische Universiteit Eindhoven; 2013.

52. Wiebe EN, Lamb A, Hardy M, Sharek D. Measuring engagement in video game-based environments: Investigation of the User Engagement Scale. Comput Hum Behav 2014; 32:123-132.

53. Hawker S, Payne S, Kerr C, et al. Appraising the evidence: Reviewing disparate data systematically. Qual Health Res 2002; 12:1284-1299.

54. Armijo-Olivo S, Stiles CR, Hagen NA, et al. Assessment of study quality for systematic reviews: A comparison of the Cochrane Collaboration Risk of Bias Tool and the Effective Public Health Practice Project Quality Assessment Tool: Methodological research. J Eval Clin Pract 2012; 18:12-18.

55. Barnett LM, Ridgers ND, Reynolds J, et al. Playing Active Video Games may not develop movement skills: An intervention trial. Prev Med Rep 2015; 2:673-678.

56. Direito A, Jiang Y, Whittaker R, Maddison R. Apps for IMproving FITness and increasing physical activity among young people: The AIMFIT pragmatic randomized controlled trial. J Med Internet Res 2015; 17:e210.

57. Dixon R, Maddison R, Ni Mhurchu C, et al. Parents' and children's perceptions of active video games: A focus group study. J Child Health Care 2010; 14:189-199.

58. Hale AR, Young VL, Grand A, McNulty CA. Can gaming increase antibiotic awareness in children? A mixedmethods approach. JMIR Serious Games 2017; 5:e5.

59. Simons M, de Vet E, Hoornstra S, et al. Adolescents' views on active and non-active videogames: A focus group study. Games Health J 2012; 1:211-218.
60. Bruggers CS, Baranowski S, Beseris M, et al. A prototype exercise-empowerment mobile video game for children with cancer, and its usability assessment: Developing digital empowerment interventions for pediatric diseases. Front Pediatr 2018; 6:69.

61. Kim HK, Leve LD. Substance use and delinquency among middle school girls in foster care: A three-year follow-up of a randomized controlled trial. J Consul Clin Psychol 2011; 79:740-750.

62. Ledoux T, Griffith M, Thompson D, et al. An educational video game for nutrition of young people: Theory and design. Simul Gaming 2016; 47:490-516.

63. Thompson DI, Cantu D, Callender C, et al. Photorealistic avatar and teen physical activity: Feasibility and preliminary efficacy. Games Health J 2018; 7:143-150.

64. Beasley N, Sharma S, Shegog R, et al. The quest to lava mountain: Using video games for dietary change in children. J Acad Nutr Diet 2012; 112:1334-1336.

65. Banos RM, Cebolla A, Oliver E, et al. Efficacy and acceptability of an Internet platform to improve the learning of nutritional knowledge in children: The ETIOBE Mates. Health Educ Res 2013; 28:234-248.

66. Bissell K, Cui Z, Meadows CW. A Wii, a Mii, and a new me? Testing the effectiveness of Wii exergames on children's enjoyment, engagement, and exertion in physical activity. Int J Child Health Hum Dev 2014; 7:37-47.

67. Parisod H, Pakarinen A, Axelin A, et al. Designing a health-game intervention supporting health literacy and a tobacco-free life in early adolescence. Games Health J 2017; 6:187-199.

68. Cates JR, Fuemmeler BF, Diehl SJ, et al. Developing a serious videogame for preteens to motivate HPV vaccination decision making: land of secret gardens. Games Health J 2018; 7:51-66.

69. Gariepy AM, Hieftje K, Pendergrass T, et al. Development and feasibility testing of a videogame intervention to reduce high-risk sexual behavior in black and Hispanic adolescents. Games Health J 2018; 7:393-400.

70. Cheek C, Fleming T, Lucassen MF, et al. Integrating health behavior theory and design elements in serious games. JMIR Ment Health 2015; 2:e11.

71. Bul K, Franken IHA, Van der Oord S, et al. Development and user satisfaction of "plan-it commander," a serious game for children with ADHD. Games Health J 2015; 4: 502-512.

72. De Vet E, Simons M, Wesselman M. Dutch children and parents' views on active and non-active video gaming. Health Promot Int 2014; 29:235-243.

73. McKenzie S, Bangay S, Barnett L, et al. Design elements and feasibility of an organized multiplayer mobile active videogame for primary school-aged children. Games Health J 2014; 3:379-387.

74. Enah C, Piper K, Moneyham L. Qualitative evaluation of the relevance and acceptability of a web-based HIV prevention game for rural adolescents. J Pediatr Nurs 2015; 30:321-328.

75. Lau PWC, Lau EY, Wang JJ, et al. A pilot study of the attractive features of active videogames among Chinese Primary School Children. Games Health J 2017; 6:87-96.

76. Li BJ, Lwin MO. Player see, player do: Testing an exergame motivation model based on the influence of the self avatar. Comput Hum Behav 2016; 59:350-357.

77. Thompson D, Cantu D, Rajendran M, et al. Development of a teen-focused exergame. Games Health J 2016; 5:342-356. 
78. Van Cleemput K, Vandebosche H, Poels K, et al. The development of a serious game on cyberbullying: A concept test. In: Vollink T, Dehue F, McGuckin C, eds. Cyberbullying: From Theory to Intervention. Abingdon, UK: Psychology Press; 2015, pp. 106-124.

79. Arnab S, Brown K, Clarke S, et al. The development approach of a pedagogically-driven serious game to support Relationship and Sex Education (RSE) within a classroom setting. Comput Educ 2013; 69:15-30.

80. Kayali F, Silbernagl M, Peters K, et al. Design considerations for a serious game for children after hematopoietic stem cell transplantation. Entertain Comput 2016; 15:5773.

81. Schwarz A, Mertens L, Simons M, et al. Which game narratives do adolescents of different gameplay and sociodemographic backgrounds prefer? A mixed-methods analysis. Games Health J 2019; 8:195-204.

82. Fernandes Davies V, Mafra R, Beltran A, et al. Children's cognitive and affective responses about a narrative versus a non-narrative cartoon designed for an active videogame. Games Health J 2016; 5:114-119.

83. Bouris A, Mancino J, Jagoda P, et al. Reinvigorating adolescent sexuality education through alternate reality games: The case of The Source. Sex Educ-Sex Soc Learn 2016; 16:353-367.

84. Blackman KC, Zoellner J, Kadir A, et al. Examining the feasibility of smartphone game applications for physical activity promotion in middle school students. Games Health J 2015; 4:409-419.

85. Baghaei N, Nandigam D, Casey J, et al. Diabetic Mario: Designing and evaluating mobile games for diabetes education. Games Health J 2016; 5:270-278.

86. Dunwell I, Dixon R, Morosini D. A Mobile Serious Game for Lifestyle Change: Conveying nutritional knowledge and motivation through play. Paper presented at 2015 International Conference on Interactive Mobile Communication Technologies and Learning, Thessaloniki, Greece, 2015.

87. Burges Watson D, Adams J, Azevedo LB, Haighton C. Promoting physical activity with a school-based dance mat exergaming intervention: Qualitative findings from a natural experiment. BMC Public Health 2016; 16:609.

88. Lison JF, Ausias C, Guixeres J, et al. Competitive active video games: Physiological and psychological responses in children and adolescents. Paediatr Child Health 2015; 20:373.

89. Verhoeven K, Abeele VV, Gers B, Seghers J. Energy expenditure during Xbox Kinect play in early adolescents: The relationship with player mode and game enjoyment. Games Health J 2015; 4:444-451.

90. Corepal R, Best P, O’Neill R, et al. Exploring the use of a gamified intervention for encouraging physical activity in adolescents: A qualitative longitudinal study in Northern Ireland. BMJ Open 2018; 8:e019663.

91. Garde A, Umedaly A, Abulnaga SM, et al. Assessment of a mobile game ("MobileKids Monster Manor") to promote physical activity among children. Games Health J 2015; 4:149-158.

92. Blanson Henkemans OA, Bierman BP, Janssen J, et al. Using a robot to personalise health education for children with diabetes type 1: A pilot study. Patient Educ Couns 2013; 92:174-181.

93. Xu Y, Poole ES, Miller AD, et al. Designing pervasive health games for sustainability, adaptability and sociability.
Proceedings of the International Conference on the Foundations of Digital Games (FDG'12), Raleigh, NC, 2012.

94. Ching CC, Stewart MK, Hagood DE, Rashedi RN. Representing and reconciling personal data and experience in a wearable technology gaming project. IEEE Trans Learn Technol 2016; 9:342-353.

95. Robertson J, Jepson R, Macvean A, Gray S. Understanding the importance of context: A qualitative study of a location-based exergame to enhance school children's physical activity. PLoS One 2016; 11:e0160927.

96. Hagood D, Ching CC, Schaefer S. Integrating physical activity data in videogames with user-centered dashboards. Proceedings of the Sixth International Conference on Learning Analytics and Knowledge (LAK'16), Edinburgh, UK, 2016.

97. Molnar A, Kostkova P. Gaming to master the gameGame usability and game mechanics. 2014 IEEE 3rd International Conference on Serious Games and Applications for Health, Rio de Janeiro, Brazil, 2014.

98. Molnar A, Kostkova P. Ubiquitous bugs and drugs education for children through mobile games. Proceedings of the 6th International Conference on Digital Health Conference, Montréal, Québec, Canada, 2016.

99. Sun H. Exergaming impact on physical activity and interest in elementary school children. Res Q Exerc Sport 2012; 83:212-220.

100. Abbott RA, Smith AJ, Howie EK, et al. Effects of home access to active videogames on child self-esteem, enjoyment of physical activity, and anxiety related to electronic games: Results from a randomized controlled trial. Games Health J 2014; 3:260-266.

101. Clevenger KA, Howe CA. Energy cost and enjoyment of active videogames in children and teens: Xbox $360 \mathrm{Ki}-$ nect. Games Health J 2015; 4:318-324.

102. Graves LE, Ridgers ND, Williams K, et al. The physiological cost and enjoyment of Wii Fit in adolescents, young adults, and older adults. J Phys Act Health 2010; 7: 393-401.

103. Penko AL, Barkley JE. Motivation and physiologic responses of playing a physically interactive video game relative to a sedentary alternative in children. Ann Behav Med 2010; 39:162-169.

104. Macias E, Garcia O, Moreno P, et al. Glooveth: Healthy living, fun and serious gaming. Stud Health Technol Inform 2012; 172:180-184.

105. Shegog R, Markham C, Peskin M, et al. "It's your game": An innovative multimedia virtual world to prevent HIV/ STI and pregnancy in middle school youth. Stud Health Technol Inform 2007; 129:983-987.

106. Farrell D, Kostkova P, Weinberg J, et al. Computer games to teach hygiene: An evaluation of the e-Bug junior game. J Antimicrob Chemother 2011; 66(Suppl. 5):v39-v44.

107. Chomutare T, Johansen SG, Hartvigsen G, Arsand E. Serious game co-design for children with type 1 diabetes. In: Mantas J, Hasman A, Gallos G, et al., eds. Unifying the Applications and Foundations of Biomedical and Health Informatics, Volume 226. Amsterdam, the Netherlands: IOS Press; 2016, pp. 83-86.

108. Grabowski D. Health identity, participation and knowledge: A qualitative study of a computer game for health education among adolescents in Denmark. Health Educ J 2013; 72:761-768.

109. Birk MV, Atkins C, Bowey JT, Mandryk RL. Fostering intrinsic motivation through avatar identification in digital 
games. Proceedings of the $2016 \mathrm{CHI}$ Conference on Human Factors in Computing Systems (CHI'16), San Jose, CA, 2016.

110. Abdul Jabbar AI, Felicia P. Gameplay engagement and learning in game-based learning: A systematic review. Rev Educ Res 2015; 85:740-779.

111. Lu AS, Kharrazi H, Gharghabi F, Thompson D. A systematic review of health videogames on childhood obesity prevention and intervention. Games Health J 2013; 2:131-141.

112. Lu AS, Kharrazi H. A state-of-the-art systematic content analysis of games for health. Games Health J 2018; $7: 1-15$.

113. Lu AS. Narrative in exergames: Thoughts on procedure, mechanism, and others. Games Health J 2015; 4:19-24.

114. Lyons EJ, Baranowski T, Basen-Engquist KM, et al. Testing the effects of narrative and play on physical activity among breast cancer survivors using mobile apps: Study protocol for a randomized controlled trial. BMC Cancer 2016; 16:202.

115. Clark DB, Tanner-Smith EE, Killingsworth SS. Digital games, design, and learning: A systematic review and meta-analysis. Rev Educ Res 2016; 86:79-122.

116. DeSmet A, Shegog R, Van Ryckeghem D, et al. A systematic review and meta-analysis of interventions for sexual health promotion involving serious digital games. Games Health J 2015; 4:78-90.

117. Hookham G, Nesbitt K, Kay-Lambkin F. Comparing usability and engagement between a serious game and a traditional online program. Proceedings of the Australasian Computer Science Week Multiconference (ACSW'16), Canberra, Australia, 2016.

118. DeShazo J, Harris L, Pratt W. Effective intervention or child's play? A review of video games for diabetes education. Diabetes Technol Ther 2010; 12:815-822.

119. Suhonen K, Väätäjä H, Virtanen T, Raisamo R. Seriously fun: Exploring how to combine promoting health awareness and engaging gameplay. Proceedings of the 12th international conference on Entertainment and media in the ubiquitous era (MindTrek'08), Tampere, Finland, 2008.
120. Thompson D, Baranowski T, Buday R, et al. Serious video games for health: How behavioral science guided the development of a serious video game. Simul Gaming 2010; 41:587-606.

121. Mekler ED, Bopp JA, Tuch AN, Opwis K. A systematic review of quantitative studies on the enjoyment of digital entertainment games. Proceedings of the SIGCHI Conference on Human Factors in Computing Systems (CHI' 14), Toronto, Ontario, Canada, 2014.

122. Poels K, De Kort Y, Ijsselsteijn W. It is always a lot of fun!: Exploring dimensions of digital game experience using focus group methodology. Proceedings of the 2007 conference on Future Play (Future Play'07), Toronto, Ontario, Canada, 2007.

123. Michie S, Yardley L, West R, et al. Developing and evaluating digital interventions to promote behavior change in health and health care: Recommendations resulting from an international workshop. J Med Internet Res 2017; 19:e232.

124. Pelletier C. Gaming in context: How young people construct their gendered identities in playing and making games. In: Kafai YB, Heeter C, Denner J, eds. Beyond Barbie and Mortal Kombat: New Perspectives on Gender and Gaming. Cambridge, MA: MIT Press; 2008, pp. 145160.

125. Consalvo M, Dutton N. Game analysis: Developing a methodological toolkit for the qualitative study of games. Game Stud 2006; 6:1-17.

126. Malliet S. Adapting the principles of ludology to the method of video game content analysis. Game Studies 2007; 7 .

Address correspondence to: Ann DeSmet, PhD Clinical and Health Psychology Université Libre de Bruxelles 50 av. F.D. Roosevelt B-1050 Bruxelles, Belgium

E-mail: ann.desmet@ulb.be 